\title{
AGENTES ANTIASMÁTICOS MODERNOS: ANTAGONISTAS DE RECEPTORES DE LEUCOTRIENOS CISTEÍNICOS
}

Lídia Moreira Lima*, Carlos Alberto Manssour Fraga e Eliezer J. Barreiro

Departamento de Fármacos, Faculdade de Farmácia, Universidade Federal do Rio de Janeiro, Cidade Universitária, CP 68006, 21944-970 Rio de Janeiro - RJ

Recebido em 9/8/01; aceito em 4/10/01

\begin{abstract}
MODERN ANTIASTHMATIC DRUGS: CYSTEINYL LEUKOTRIENES RECEPTORS ANTAGONISTS. In the early 1990s numerous clinical trials with antileukotriene drugs confirmed the hypothesis that cysteinyl leukotrienes are important bronchoconstrictor agents in asthma. Newly released"antiasthmatic medications include antileukotriene agents which function either by blocking the interaction of leukotrienes with receptors or by inhibiting leukotriene synthesis. Representatives of cysteinyl leukotriene receptors antagonists are zafirlukast (7), montelukast (8) and pranlukast (9). The bronchodilator efficacy and antiinflammatory property of antileukotriene drugs provided the main impetus behind their introduction as the first novel class of asthma therapy in more than 20 years.
\end{abstract}

Keywords: antileukotrienes; antiasthmatic drugs; leukotriene.

\section{INTRODUÇÃO}

A asma constitui um estado inflamatório crônico geralmente acompanhado de sinais clínicos familiares, que se somam a uma das características principais do processo de obstrução reversível das vias aéreas, o broncoespasmo ${ }^{1}$. Estes sinais, representados por dispnéia, tosse, espirro intermitente, opressão torácica e broncoconstrição, são decorrentes de processos fisiológicos como edema, recrutamento e ativação de células inflamatórias, aumento da secreção de muco e contração da musculatura lisa brônquica, seguida de hipertrofia e hiperplasia muscular ${ }^{1-3}$.

A asma brônquica é uma fisiopatologia genericamente classificada em asma extrínseca e intrínseca, classificação que decorre da participação (ou não) de mecanismos alergênicos envolvendo a imunoglobulina $\mathrm{E}(\mathrm{IgE})^{4-8}$. O processo asmático é basicamente dividido em duas fases, a saber: a) fase imediata, causada principalmente por espasmo do músculo liso bronquial, caracterizando a resposta de broncoconstrição típica desta fisiopatologia; b) fase tardia, ocorre em tempo variável após a exposição ao estímulo antigênico, ocasionada essencialmente por uma resposta inflamatória aguda que normalmente progride a um estado inflamatório crônico ${ }^{9-11}$. Esta última fase é responsável pela principal característica da asma, i.e., a hiperreatividade brônquica, que se refere à sensibilidade anormal a ampla faixa de estímulos como substâncias químicas irritantes, ar frio, fármacos, alérgenos, poluentes atmosféricos, entre outros ${ }^{12}$. Ademais, a resposta asmática de fase tardia é caracterizada por uma inflamação do tipo eosinofílica, que se relaciona de forma direta com o desenvolvimento da hiperreatividade brônquica ${ }^{13-15}$.

\section{PREVALÊNCIA E MORTALIDADE DA ASMA BRÔNQUICA}

A asma representa uma das condições patológicas crônicas de maior incidência no mundo contemporâneo. Era uma fisiopatologia rara no ínicio do século, entretanto, sua prevalência em países industrializados tem crescido assustadoramente, assumindo proporções epidêmicas, acometendo ca. 155 milhões de pessoas por todo mundo ${ }^{16-18}$.

*e-mail: lidiaml@yahoo.com

http://www.farmacia.ufrj.br/lassbio
O custo do tratamento de pacientes asmáticos é substancial, estimando-se gastos da ordem de US\$ 6 bilhões nos EUA, US\$ 3 bilhões na Alemanha e US\$ 1,6 bilhões anuais na Inglatera ${ }^{17}$, acreditando-se que o custo sócio-econômico desta fisiopatologia supere o custo combinado de infecções como a tuberculose e a síndrome da imunodeficiência adquirida (AIDS) ${ }^{\#}$, rendendo à indústria farmacêutica um lucro da ordem de US\$ 5,5 bilhões/ano.

A constatação do crescimento no número de mortes associadas à asma (Figura 1) caracteriza a letalidade desta fisiopatologia ${ }^{19-24}$ e justifica o investimento destinado à busca de novos agentes antiasmáticos
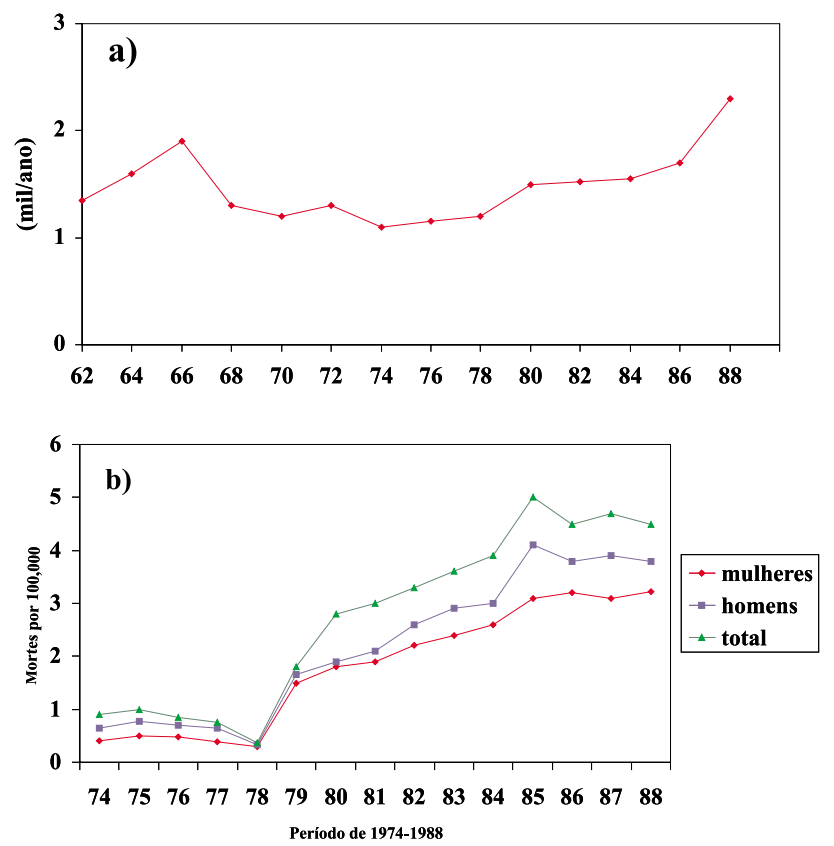

Figura 1. a) Letalidade da asma na Inglaterra (mil/ano) no periodo de 1962-198856 b) Letalidade da asma na Itália (mil/ano) no periodo de 1974$1988^{22}$

\# http://www.pharminfo.com/pubs/pnn/ pnn25_16. html 
mais eficazes que, juntamente com o tratamento profilático, permitam reverter o significativo impacto sócio-econômico desta patologia $^{25,26}$. Dados da Organização Mundial da Saúde revelam que o coeficiente global de mortalidade por asma no Brasil apresenta uma tendência à elevação, a partir do ínicio da década de 90 , estimandose média de 2,05 óbitos/ano em cada 100,000 habitantes ${ }^{27}$.

\section{PATOGENIA DO PROCESSO ASMÁTICO}

A fisiopatologia do processo asmático está relacionada aos mecanismos de ativação, produção e liberação de mediadores químicos endógenos de células sanguíneas e teciduais, e.g. mastócitos, eosinófilos, macrófagos, linfócitos, basófilos e plaquetas ${ }^{28-32}$. Nestas últimas, os estudos pioneiros de Capron e colaboradores ${ }^{33}$ demonstraram a presença de receptores de imunoglobulina $\mathrm{E}$ (IgE) de baixa afinidade ( $\left.\mathrm{FC}_{\varepsilon} \mathrm{RII}\right)$ em sua superfície membranar ${ }^{33}$. De forma análoga, a presença de receptores de $\operatorname{IgE}$ de alta afinidade $\left(\mathrm{FC}_{\varepsilon} \mathrm{RI}\right)^{34-36}$ na superfície membranar de mastócitos, confere a estas células importante papel no desenvolvimento da resposta de fase imediata da asma brônquica, por meio da liberação de autacóides aminados, como a histamina e serotonina, e lipídicos, tais como os leucotrienos cisteínicos, $\mathrm{LTC}_{4}, \mathrm{LTD}_{4}, \mathrm{LTE}_{4}$ e prostaglandina $\mathrm{D}_{2}\left(\mathrm{PGD}_{2}\right)$, que atuam sinergicamente no desenvolvimento da broncoconstrição característica desta fase do processo asmático (Figura 2). Ademais, a ativação e degranulação de mastócitos por estímulos antigênicos ${ }^{37,38}$ leva à liberação de citocinas como o fator de necrose tumoral alfa (TNF $\alpha$ ) e as diferentes interleucinas (IL-1, IL-4, IL-5, IL-8 e IL-13) que agem de forma sinérgica na resposta inflamatória característica da fase tardia da asma brônquica ${ }^{28}$ (Figura 2). Portanto, os mastócitos são considerados como células efetoras de respostas alérgicas associadas a IgE, contribuindo significativamente na expressão de as- pectos da resposta imune adquirida em reações de fase tardia como a inflamação crônica-alérgica das vias aéreas ${ }^{39}$.

\section{Terapia antiasmática clássica}

O arsenal de fármacos disponível para o tratamento clínico da asma pode ser dividido em duas classes terapêuticas, i.e., broncodilatadores e antiinflamatórios ${ }^{41-43}$. Como exemplos de agentes terapêuticos broncodilatadores podemos citar: os agonistas $\beta_{2}$ adrenérgicos ${ }^{44}$, anticolinérgicos ${ }^{45}$, metilxantinas ${ }^{46}$ e moduladores de canais de potássio ${ }^{41}$. Por sua vez, os corticosteróides ${ }^{47}$, antagonistas de bradicinina ${ }^{48}$, anti-histamínicos ${ }^{49}$, inibidores de fosfolipase $\mathrm{A}_{2}$ $\left(\mathrm{PLA}_{2}-\mathrm{i}\right)^{50}$, inibidores de tromboxana sintase $(\mathrm{TXSi})^{51}$, antagonistas de receptores de $\mathrm{TXA}_{2}$ (TPant) $^{52}$, antagonistas de receptores de PAF (PAFant) ${ }^{53}$, inibidores de LTA $_{4}$-hidrolase ${ }^{54}$, inibidores de 5lipoxigenase (5-LO-i) $)^{55}$, são exemplos de agentes antiinflamatórios, úteis para o tratamento do processo asmático.

De fato, uma comparação entre os fármacos mais prescritos para o tratamento da asma brônquica versus o aumento no índice de mortalidade, em países como o Reino Unido e Itália (Figura $1 v s$. Figura 3), evidencia a baixa eficácia dos antiasmáticos clássicos utilizados no tratamento sintomático desta fisiopatologia, confirmando a urgente necessidade de novas estratégias terapêuticas para um tratamento curativo quiçá preventivo da asma.

\section{Terapia antiasmática moderna}

O reconhecimento da asma brônquica como uma resposta inflamatória, fruto do avanço da farmaco-imunologia, biologia molecular e engenharia genética, permitiu a identificação de novos alvos terapêuticos úteis para seu tratamento ${ }^{27,57-61}$.

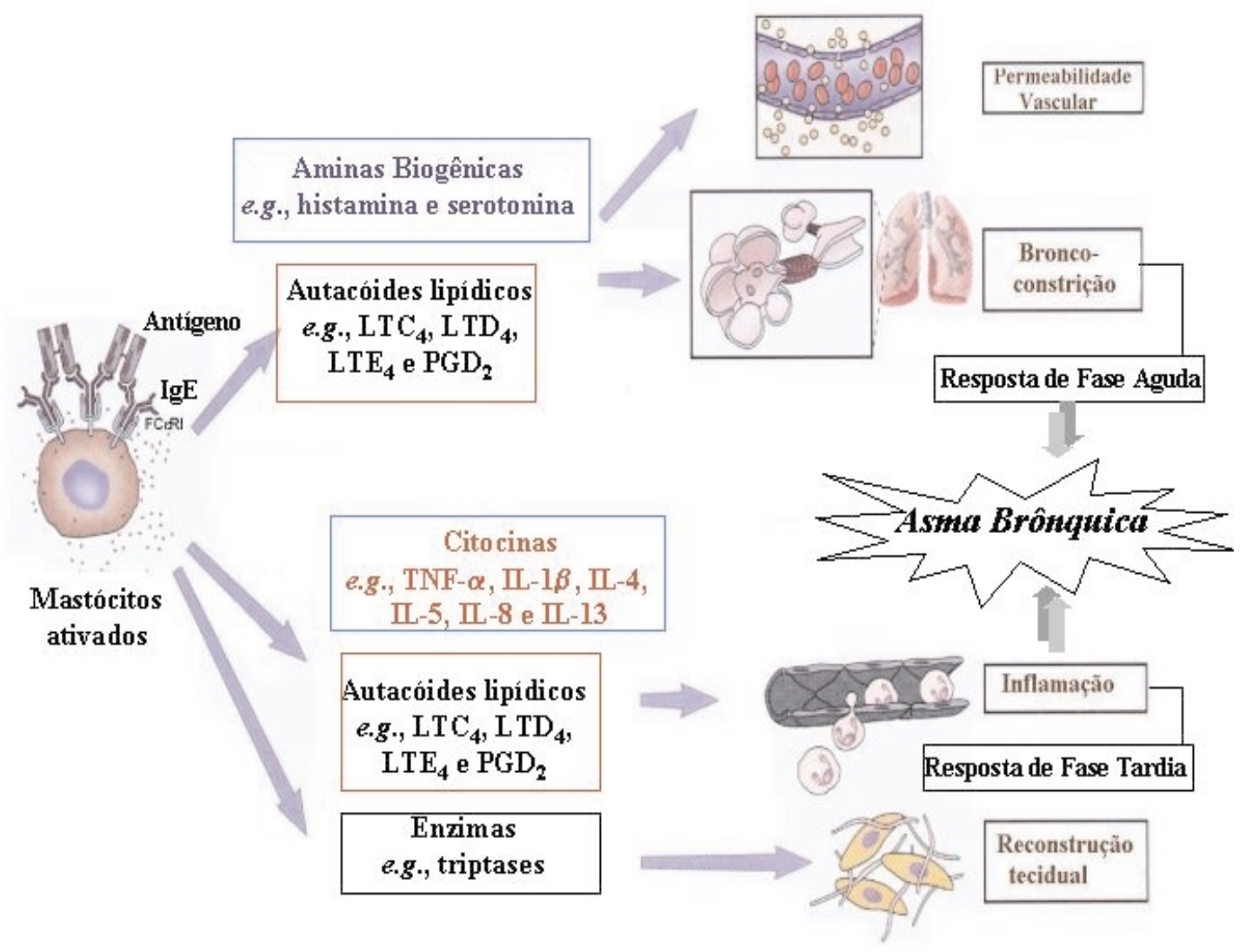

Figura 2. Efeitos biológicos de mediadores químicos liberados de mastócitos ativados ${ }^{40}$ 


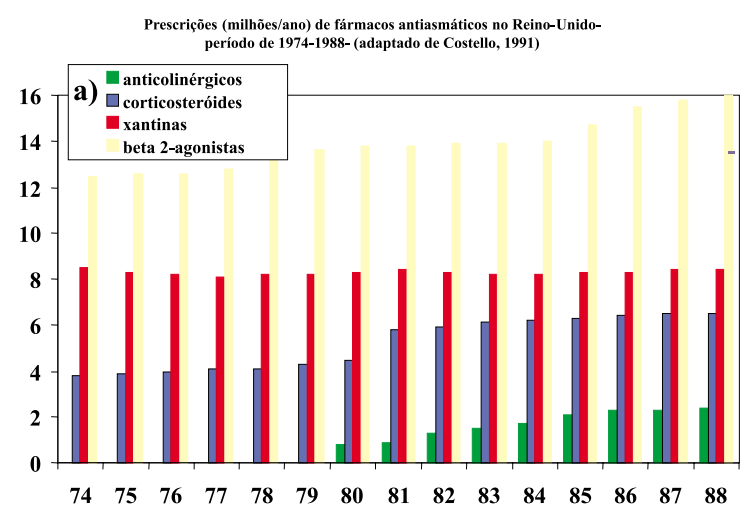

b)

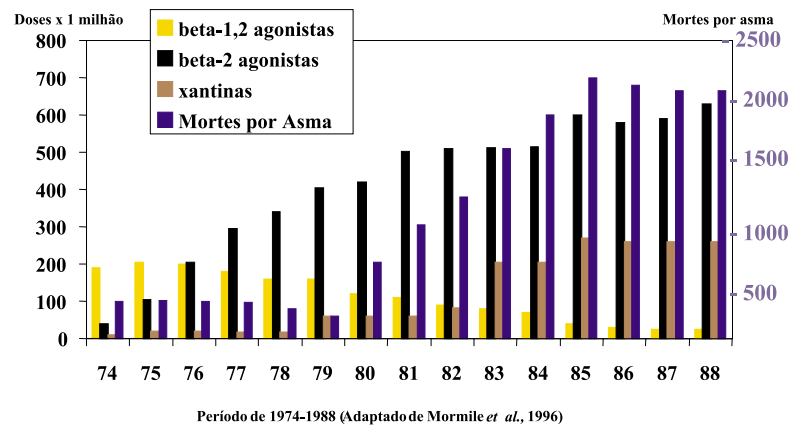

Figura 3. a) Relação dos principais fármacos antiasmáticos prescritos no Reino Unido, no periodo de 1974-198856; b) Relação dos principais fármacos antiasmáticos prescritos na Itália, no periodo de 1974-1988, em relação ao número de mortes por asma ${ }^{22}$

De um modo geral, a terapia antiasmática moderna envolve fármacos que atuam no processo inflamatório desta patologia, tais como inibidores da eosinofilia ${ }^{62}$, bloqueadores da adesão celular ${ }^{58}$, moduladores de citocinas $^{63-65}$, inibidores de fosfodiesterases do tipo
$4^{66,67}$, inibidores duplos do fator de necrose tumoral alfa e de fosfodiesterases (TNF- $\alpha /$ PDEs) e os antileucotrienos ${ }^{68}$ (Figura 4), ou seja, substâncias que atuam inibindo a produção ou bloqueando a ação dos leucotrienos, através da inibição enzimática de sua bioformação ou como antagonista de seus receptores, respectivamente (Figura 5). Esta última abordagem terapêutica representa uma autêntica e moderna inovação na terapia da asma brônquica, exemplificada pelos fármacos zafirlukast (Accolate $\left.{ }^{\circledR}, 7\right)$, montelukast $\left(\right.$ Singulair $\left.^{\circledR}, 8\right)$ e pranlukast $\left(\right.$ Ultair $\left.^{\circledR}, 9\right)$ recentemente lançados, que exercem seu mecanismo de ação antagonizando seletivamente os receptores de leucotrienos cisteínicos ${ }^{69}$.

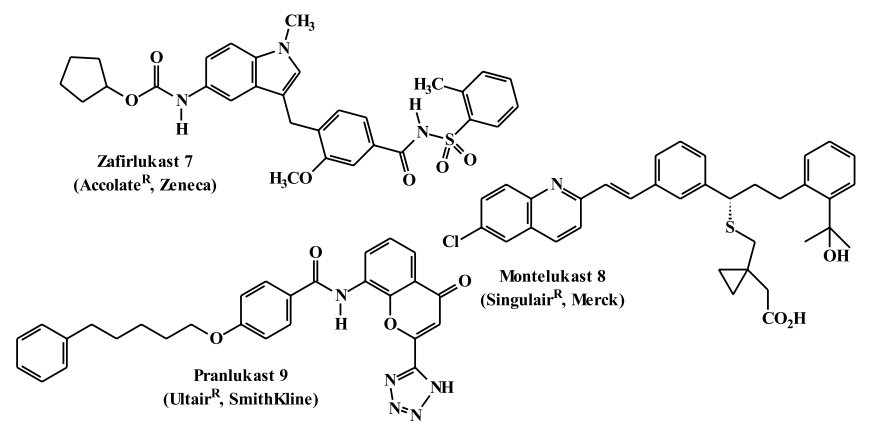

\section{Antileucotrienos}

O mercado mundial de antagonistas de receptores de leucotrienos (CysLTant) movimenta bilhões de dólares e cresce anualmente*, por representar a melhor alternativa terapêutica para o tratamento da asma, suplantando os agentes antiasmáticos convencionais (broncodilatadores e corticosteróides**). A recente aprovação pelo FDA (Food and Drug Administration) do zafirlukast (Accolate $\left.{ }^{\circledR}, 7\right)^{71}$, primeiro antagonista de receptores de leucotrienos cisteínicos de eficácia terapêutica comprovada, lançado pelo laboratório Zeneca, em 1999, iniciou uma nova era no tratamento da asma e consolidou a importância destes autacóides como alvo terapêutico para o planejamento de fármacos eficazes para o controle e tratamento da fase aguda e crônica da asma brônquica (Figura 5).<smiles>COc1cc(CCc2ccc(C3=Cc4ccccc4C4=NCCN34)cc2)cc(OC)c1OC</smiles><smiles>O=C(O)C(c1ccc(OCc2ccc3ccccc3n2)cc1)C1CCCC1</smiles><smiles>COc1ccc(C2CC(=O)N(C)C2)cc1OC1CCCC1</smiles><smiles>COc1ccc(C2(C#N)CCC(C(=O)O)CC2)cc1OC1CCCC1</smiles><smiles>COc1ccc(C(CC#N)N2C(=O)c3ccccc3C2=O)cc1OC1CCCC1</smiles><smiles>CC(c1cc2ccccc2s1)N(O)C(N)=O</smiles>

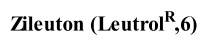
Antileucotrieno

Figura 4. Exemplos das principais estratégias antiasmáticas modernas

*http://pharminfo.com

**A despeito da potencial atividade antiinflamatória dos corticosteróides, sua utilização no tratamento da asma crônica é contra-indicado face aos diversos efeitos colaterais sistêmicos, mecanismo de ação dependentes, provenientes da utilização continuada desta classe terapêutica . 


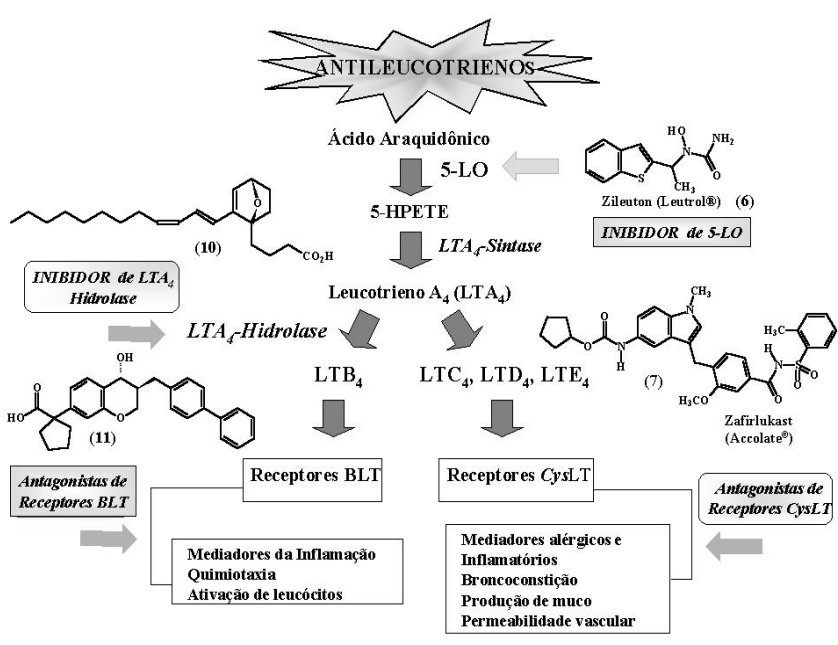

Figura 5. Representação dos principais alvos terapêuticos provenientes da inibição da biossintese elou bloqueio dos receptores de leucotrienos

\section{Leucotrienos}

Os leucotrienos (LTs) são icosanóides oriundos da cascata do ácido araquidônico (CAA $)^{72}$, e classificados como leucotrienos cisteínicos (CysLT), $\mathrm{LTC}_{4}, \mathrm{LTD}_{4}$ e $\mathrm{LTE}_{4}$, outrora conhecidos como componentes da substância de reação lenta da anafilaxia (SRS-A), descoberta em 1938 por Feldberg e Kellaway, e quimicamente caracterizada por Bengt Sammuelsson no final da década de $70^{73}$; e o leucotrieno pró-inflamatório $\mathrm{LTB}_{4}{ }^{72}$.

As principais propriedades farmacológicas destes icosanóides, oriundas de sua interação com receptores específicos de membrana incluem: broncoconstrição, aumento da permeabilidade vascular, produção de muco, liberação de enzimas lisossômicas, quimiotaxia, ativação de leucócitos e vasoconstrição da musculatura lisa, e refletem seu envolvimento em fisiopatologias inflamatórias como asma, rinite alérgica, artrite reumatóide e psoríase $\mathrm{e}^{1,2,72-76}$.

\section{Biossíntese e catabolismo dos leucotrienos}

A etapa chave na biossíntese dos LTs constitui a formação do intermediário hidroperóxido instável, o ácido 5(S)-hidroperóxido$6(E), 8(Z)-11(Z), 14(Z)$-eicosatetraenóico, 5-HPETE, pela ação enzimática da 5-lipoxigenase ${ }^{77}$ sobre o ácido araquidônico liberado dos fosfolipídeos de membrana por ação da fosfolipase $\mathrm{A}_{2}\left(\mathrm{PLA}_{2}\right)$.

As lipoxigenases (5-LO, 12-LO e 15-LO) constituem família de enzimas citoplasmáticas, classificadas de acordo com a posição na qual oxidam o ácido araquidônico (AA ${ }^{78}$. Desta forma, a 5lipoxigenase (5-LO) é aquela que oxida a insaturação em C-5 deste ácido graxo essencial, sendo a mais importante destas enzimas, promovendo a bioformação dos leucotrienos (Figura 6). A 5-LO é uma enzima citoplasmática ${ }^{79,80}$, ativada após transporte intracelular, dependente de íons $\mathrm{Ca}^{+2}$ (cálcio) e ATP (adenosina trifosfato), em direção à membrana plasmática, onde se associa à proteína denominada proteína ativadora de 5-LO (FLAP) $)^{79-81}$. Uma vez associada à FLAP, a 5-LO catalisa a oxigenação da posição C-5 do AA, levando à formação do 5-HPETE, que por ação subseqüente da enzima LTA $_{4}$ sintase, presente em mastócitos, eosinófilos, basófilos, plaquetas e monócitos ${ }^{80}$, é biotransformado no intermediário epóxido ácido 5,6óxido-7,9-trans-11,14-cis-eicosatetraenóico, LTA $_{4}^{73}$. O LTA 4 , por sua vez, é substrato para duas novas enzimas a LTA $_{4}$ hidrolase ${ }^{82}$, que origina o $\mathrm{LTB}_{4}$; e a glutationa- $S$-transferase, levando à bioformação do primeiro leucotrieno cisteínico, o $\mathrm{LTC}_{4}$, que por ações seqüenciais das enzimas $\gamma$-glutamiltranspeptidase e dipeptidase originam os demais Cys-LTs, LTD $_{4}$ e $\mathrm{LTE}_{4}$, respectivamente ${ }^{81,83}$.

O catabolismo desta família de icosanóides envolve basicamente reações de $\omega$ e $\beta$-oxidação. A principal diferença refere-se ao catabolismo dos Cys-LTs, que são primeiramente metabolizados ao $\mathrm{LTE}_{4}$ (metabólito menos ativo), o qual é subseqüentemente metabolizado através de duas reações de $\omega$-oxidação, originando o

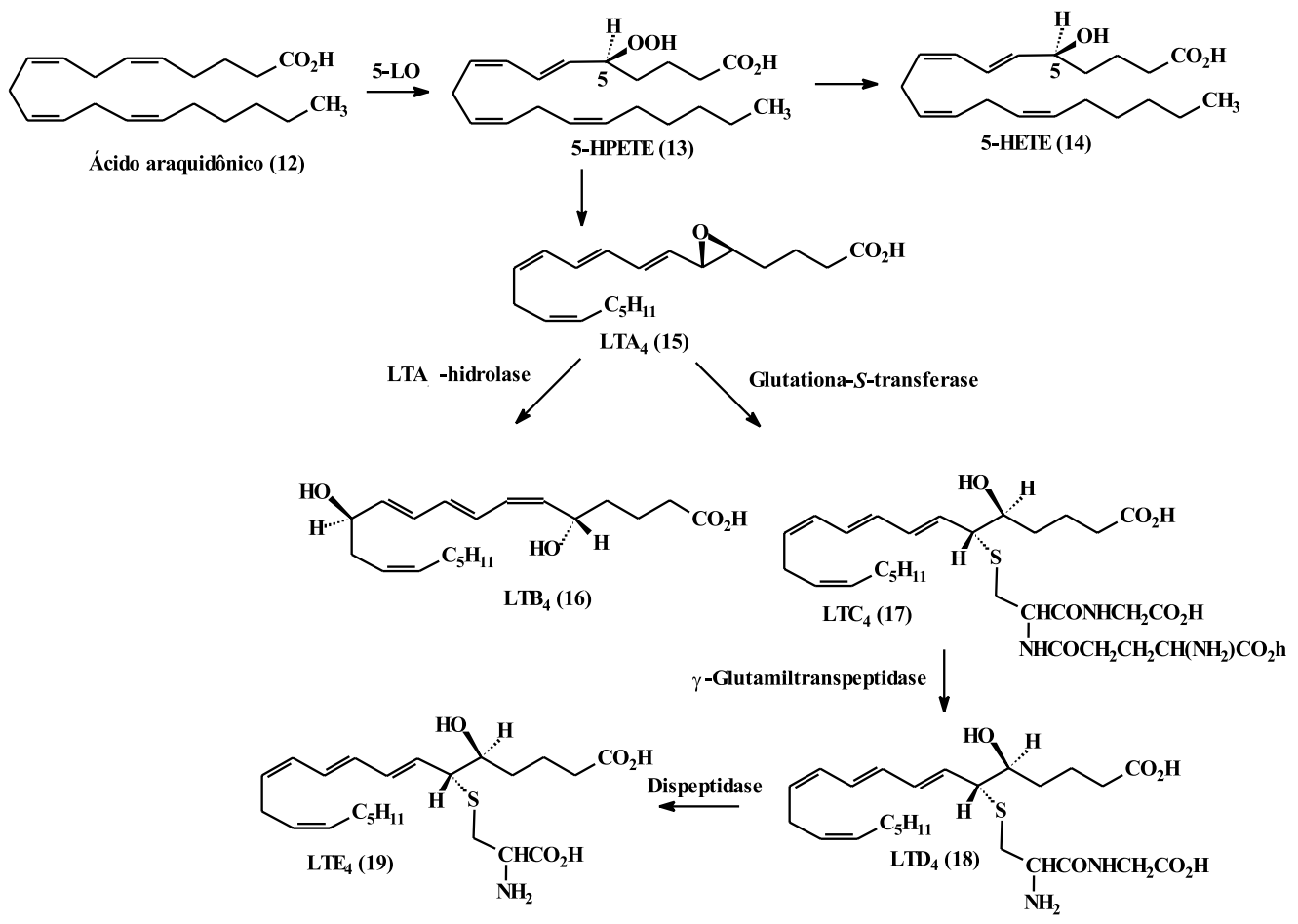

Figura 6. Bioformação dos leucotrienos 
ácido correspondente ao $\mathrm{LTE}_{4}$, e posterior reação de $N$-acetilação, seguida de $\omega$ e $\beta$-oxidação ${ }^{84}$.

\section{Classificação dos receptores de LTs}

As diferenças farmacológicas e possivelmente estruturais entre os receptores de leucotrienos cisteínicos vs. receptores de $\mathrm{LTB}_{4}$ resultaram na classificação distinta destes biorreceptores, de forma que o receptor de $\mathrm{LTB}_{4}$ é comumente chamado receptor BLT, enquanto que os receptores de leucotrienos cisteínicos são denominados receptores CysLT (IUPHAR, 1995). Nesta última categoria de receptores, estudos funcionais recentes em bioensaios com músculo liso, demonstraram a presença de subtipos de receptores CysLT classificados de acordo com sua resposta a antagonistas seletivos de $\mathrm{LTD}_{4}$ (e.g.: FPL 55712) em: $C y s \mathrm{LT}_{1}$, referente ao receptor para $\mathrm{LTD}_{4}$, e Cys $\mathrm{LT}_{2}$, para receptores de $\mathrm{LTC}_{4}{ }^{85-88}$ (Tabela 1).

Recentemente, os receptores de leucotrienos cisteínicos, Cys $\mathrm{LT}_{1}$ e $C y s \mathrm{LT}_{2}$, tiveram seus DNAs clonados, permitindo sua caracterização molecular e farmacológica e evidenciando homologia seqüencial na cadeia primária destas proteínas da ordem de $38 \%{ }^{89,90}$. Com base nestes dados, a futura elucidação da estrutura quaternária destas proteínas fornecerá subsídios para o planejamento racional de novos ligantes seletivos de biorreceptores Cys $_{1} \mathrm{LT}_{1}$ e $C y s \mathrm{LT}_{2}$.

\section{Modelo de sítio receptor Cys $_{1}$}

Baseados em estudos de modelagem molecular do $\mathrm{LTD}_{4}$, subsidiados pelos dados da relação estrutura química e atividade biológica (SAR) de uma série de antagonistas de receptores Cys LT ${ }_{1}$, Harper e colaboradores ${ }^{91}$ propuseram a primeira representação esquemática do sítio receptor $C y s \mathrm{LT}$, evidenciando as principais interações químicas envolvidas na formação do complexo receptor-bioligante. Em trabalhos subseqüentes, Salmon e Garland ${ }^{92}$ propuseram sítios específicos de ligação ao receptor $C y s \mathrm{LT}_{1}$, inferindo os requisitos estruturais mínimos necessários à interação do bioligante natural $\left(\mathrm{LTD}_{4}\right)$, exemplificadas pela presença de grupamentos ácidos carboxílicos e cisteinilglicina e de unidades estruturais ricas em elétrons (Figura 7).

Posteriormente, Zhang e colaboradores ${ }^{93}$ propuseram um modelo mais completo dos receptores $C y s \mathrm{LT}_{1}$ com a capacidade de acomodar geometricamente as diversas classes de antagonistas de receptores Cys $\mathrm{LT}_{1}$ conhecidos. Entretanto, a demonstração da importância de subunidades estruturais ácidas e aceptoras de ligação hidrogênio, assim como a comprovação experimental da presença de resíduos de arginina no sítio receptor $C y s \mathrm{LT}_{1}$, constituíram o aspecto inovador da proposta de modelo-receptor desenvolvida por estes autores $^{93}$.

Tabela 1. Subtipos de receptores de leucotrienos cisteínicos, encontrados em diferentes tecidos, seus antagonistas e o efeito farmacológico mediado pela interação ligante natural-receptor $C y s \mathrm{LT}$

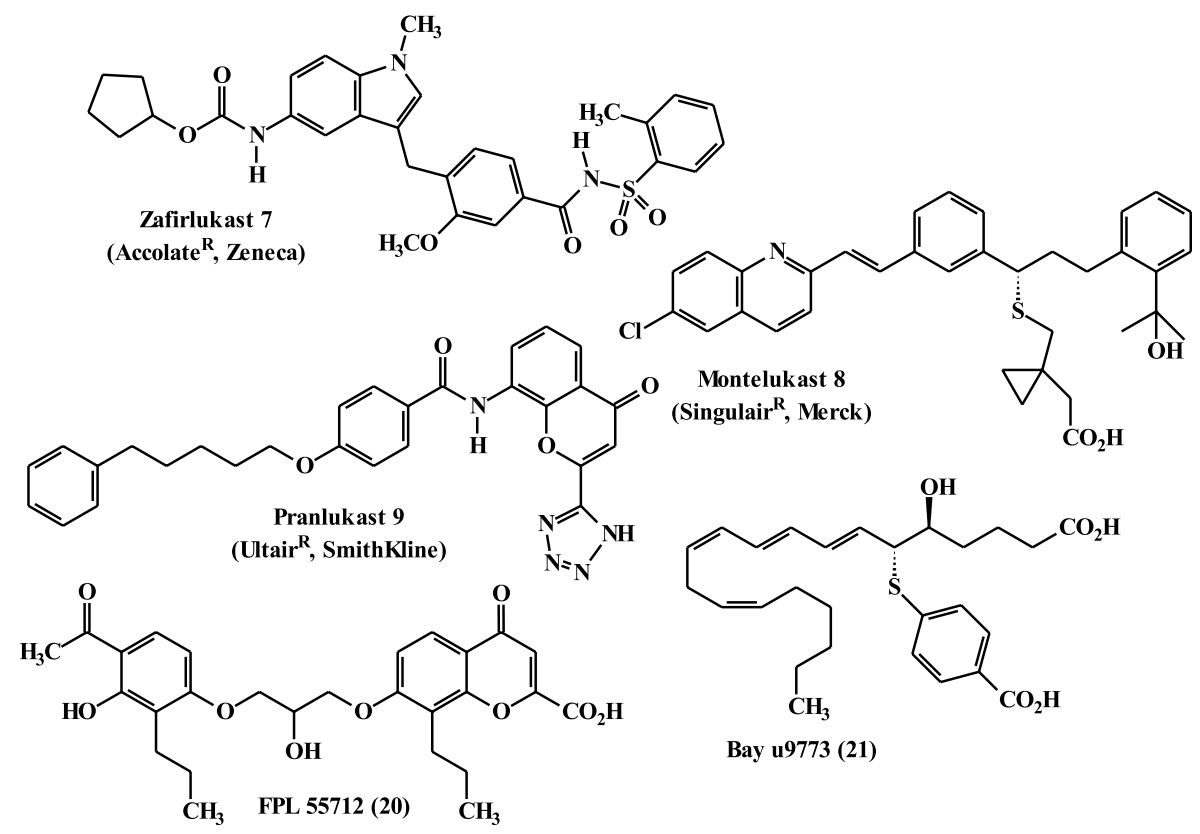

\begin{tabular}{cccc}
\hline Subtipos de receptores & Tecidos & Antagonistas & Efeito farmacológico \\
\hline$C y s \mathrm{LT}_{1}$ & traquéia e íleo de cobaias & FPL-55712 (20) Zafirlukast (7) & broncoespasmo exsudação \\
$C y s \mathrm{LT}_{1}$ & brônquios humanos & Montelukast (8) & recrutamento de eosinófilos \\
$C y s \mathrm{LT}_{1}$ & pulmão de ratos & Pranlukast $(9)$ & vasoconstrição \\
$C y s \mathrm{LT}_{2}$ & veia pulmonar humana & Bay u9773 $(21)^{\mathrm{b}}$ & respostas vasculares \\
$C y s \mathrm{LT}_{2}$ & traquéia e Îleo de Cobaias & Bay u9773 $(21)^{\mathrm{b}}$ & contração da musculatura lisa \\
$C y s \mathrm{LT}_{2}$ & traquéia e brônquios de ovelhas & Bay u9773 $(21)^{\mathrm{b}}$ & contração da musculatura lisa \\
\hline
\end{tabular}

${ }^{\text {a }}$ cobaias

${ }^{\mathrm{b}}$ Antagonista não seletivo atuando sobre ambos receptores $C y s \mathrm{LT}_{1}$ e $C y s \mathrm{LT}_{2}$ 


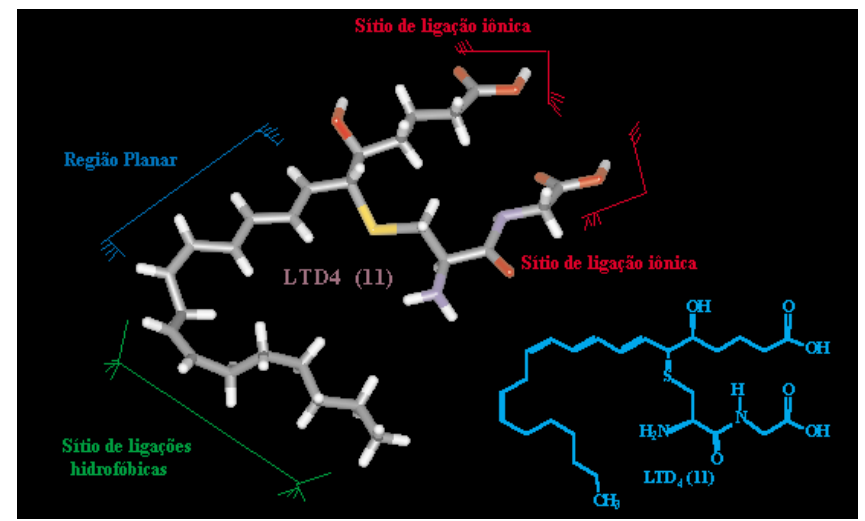

Figura 7. Principais regiões farmacofóricas de interação com o biorreceptor Cys $L T_{1}^{89}$

a)
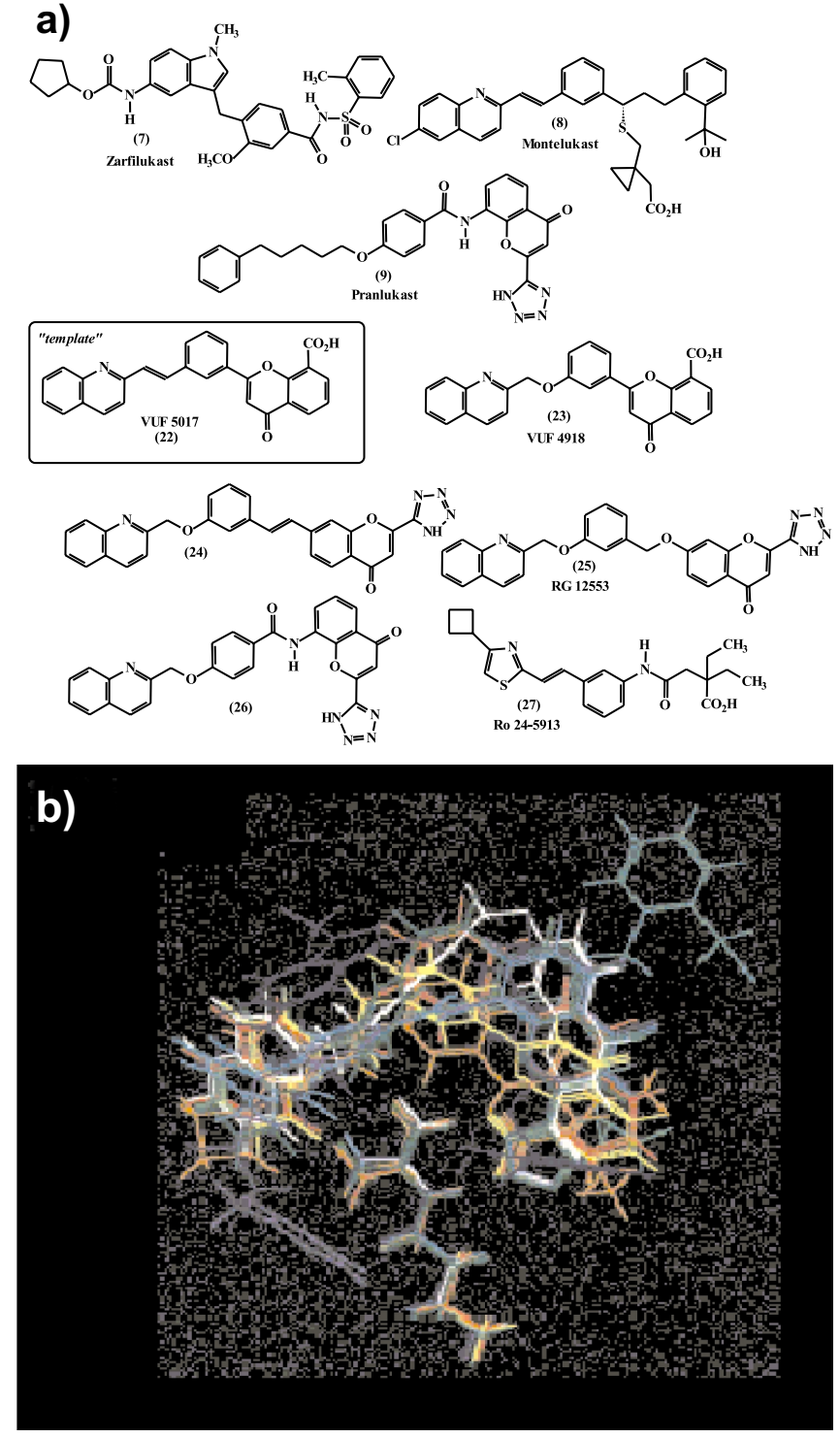

Figura 8. a) CysLTant selecionados para o estudo de modelagem molecular de Zwaagstra et al., 1998; b) Modelo topográfico de antagonistas de receptores Cys $L T_{1}$, descrito por Zwaagstra et al., 199894. VUF 5017 (amarelo); VUF 1918 (vermelho); composto 15 (verde); RG 12553 (branco); composto 26 (azul claro); Ro 24-5913 (laranja); pranlukast (purple); zafirlukast (azul); montelukast (ciano)
Dando continuidade a estes estudos, Zwaagstra e colaboradores $^{94}$ descreveram um modelo topográfico tridimensional (3D) de antagonistas de receptores $C y s \mathrm{LT}_{1}$, obtido através de estudos de modelagem molecular. Estes estudos basearam-se na sobreposição dos confôrmeros de menor energia de diferentes antagonistas de receptores $C y s \mathrm{LT}_{1}$, pertencentes à classe de antagonistas não relacionados ao $\mathrm{LTD}_{4}$ e/ou ao FPL 55712, selecionados a partir de sua potência e do grau de rigidez conformacional (Figura 8). A sobreposição foi realizada considerando os principais farmacóforos presentes nas estruturas de 7-9 e 22-27, previamente identificados usando o composto VUF 5017 (22) como modelo ("template"). A principal característica deste modelo $3 \mathrm{D}$ refere-se à determinação das posições espaciais das subunidades ácidas e lipofílicas reconhecidas como requisitos estruturais necessários ao reconhecimento molecular dos receptores Cys $\mathrm{LT}_{1}$ (Figura 8).

Mais recentemente, Palomer e colaboradores ${ }^{95}$ descreveram um modelo de alinhamento para séries estruturalmente congêneres de antagonistas de receptores $C y s \mathrm{LT}_{1}$, combinando o modelo farmacofórico proposto por Zwaagstra e colaboradores, com estudos de CoMFA ("Comparative Molecular Field Analysis"). Estes autores foram capazes de definirem as subunidades estruturais passíveis de modificações nestes antagonistas, viabilizando a otimização da interação ligante-biorreceptor, conforme ilustrado na Figura $9{ }^{95}$.

\section{Antagonistas de receptores CysLT}

De um modo geral, três abordagens distintas são utilizadas no planejamento de novos antagonistas de receptores $C y s \mathrm{LT}_{1}$ i.e.: análogos do FPL 55712 (20); derivados estruturalmente relacionados ao $\operatorname{LTD}_{4}(18)$; e análogos quimicamente não relacionados ao $\mathrm{LTD}_{4}$ e/ou ao FPL $55712^{96,97}$.

\section{Análogos ao FPL 55712 (20)}

O FPL 55712 (20) é considerado o composto protótipo de uma série de derivados hidroxiacetofenônicos ${ }^{98}$, representando a primeira geração de antagonistas sintéticos de receptores $C y_{s} \mathrm{LT}_{1}$.

a)

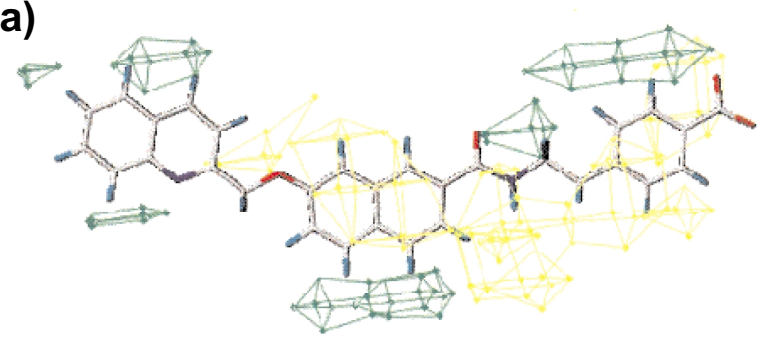

b)

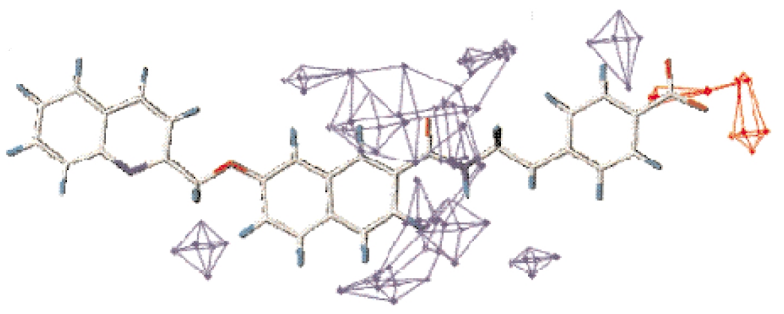

Figura 9. a) Representação gráfica do mapa de contorno estérico (CoMFA STDEV COEFF): cor amarela representando regiões estericamente favoráveis e cor verde para regiões estericamente desfavoráveis; b) Representação gráfica do mapa de contorno eletrostático (CoMFA STDEV COEFF): cor vermelha regiões favoráveis eletrostaticamente e cor azul para regiões desfavoráveis (adaptado de Palomer et al.) ${ }^{95}$ 
$\mathrm{Na}$ tentativa de superar a baixa biodisponibilidade e o inadequado tempo de meia-vida de (20), em modelos animais ${ }^{99}$, várias propostas de substituição da unidade estrutural ácida 2-cromanilcarboxílica foram efetuadas, originando os derivados L 649.923 (28), YM 16638 (29), LY 163443 (30), L 648051 (31) e LY 171883 (32) (Figura 10). Dentre estes compostos destaca-se, por sua simplicidade estrutural, o derivado (32) que apresentou melhor biodisponibilidade oral e potência antagonística relativa $(\mathrm{Ki}=66 \mathrm{nM})$. Todavia, a baixa seletividade deste derivado, evidenciada pela ação antagonista em outros biorreceptores, e.g. $\mathrm{TXA}_{2}{ }^{100,101}$, representou fator limitante ao seu uso clínico.<smiles></smiles><smiles>CCCCCCOC1CCC(C(C)CCC)CC1CCC</smiles><smiles>CCCC1CCC(OCCCCC2CNC(SCC)N2)C(CCC)C1C</smiles><smiles>CCCC1C(COC2CCC(CC3CCN(C)C3)CC2)CCC(C(C)O)C1C</smiles><smiles>CCCC1C(OCCCCC2CCCC2C)CCC(C(C)O)C1C</smiles>

Figura 10. Exemplos de antagonistas de receptores Cys $L T_{1}$ planejados por analogia estrutural ao FPL 55712(20)

\section{Antagonistas de CysLT 1 estruturalmente relacionado ao LTD}

$\mathrm{Na}$ tentativa de superar a baixa seletividade dos antagonistas análogos ao FPL 55712 (20), uma nova classe de derivados estruturalmente relacionados ao $\mathrm{LTD}_{4}$ foi sintetizada e avaliada farmacologicamente, marcando o ínicio de uma nova abordagem no planejamento de antagonistas sintéticos de receptores $C y_{S} \mathrm{LT}_{1}$, constituindo-se na segunda geração de fármacos providos de atividade antagonista $C y s \mathrm{LT}_{1}$.

O primeiro antagonista de receptores $C y s \mathrm{LT}_{1}$ planejado por analogia estrutural ao $\mathrm{LTD}_{4}(18)$ é representado pelo composto protótipo SK\&F $101132(33)^{102}$. Modificações moleculares subseqüentes na estrutura de (33), envolvendo a supressão da unidade glicina e do grupamento amino, resultaram na síntese do derivado (34), que apresentou maior potência antagonística e superior tempo de meia-vida ${ }^{102}$.
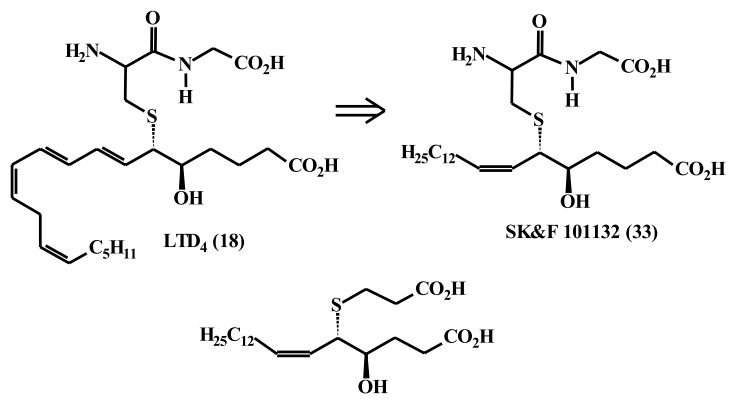

(34)

Baseados nestes promissores resultados, que demonstraram a importância farmacofórica da subunidade estrutural ácido 2-hidroxi3-tioeptadióica, uma nova série de derivados relacionados foi sintetizada e avaliada farmacologicamente, destacando-se os compostos
SKF 104.353 (35) e SKF 106.203 (36), que apresentaram alta afinidade pelos receptores Cys $\mathrm{LT}_{1}{ }^{103,104}$.
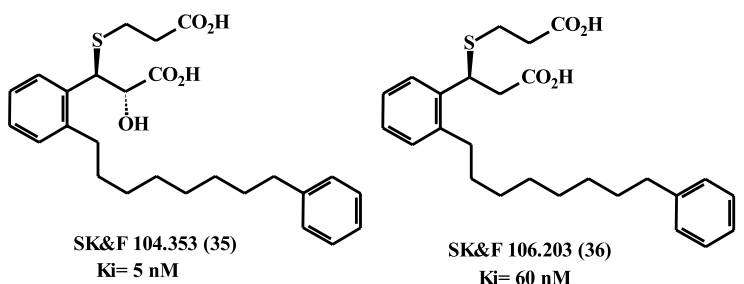

Antagonistas de receptores $C_{y s L T}$ estruturalmente não
relacionados ao $\mathrm{LTD}_{4}$ e/ou FPL 55712

A classe de derivados antagonista de receptores $C y s \mathrm{LT}_{1}$ estruturalmente não relacionados ao agonista natural, $\mathrm{LTD}_{4}$, ou ao protótipo da primeira geração de fármacos sintéticos com propriedades

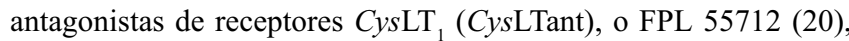
engloba famílias de derivados amino-heterocíclicos contendo os núcleos indólico ou quinolínico e inclui a classe de fármacos antileucotrienos, recentemente aprovada pelo FDA para o tratamento da asma brônquica. Exemplos desta abordagem incluem o zafirlukast (7); montelukast (8); ritolukast (37) e verlukast (38) ${ }^{42,104}$. Estes compostos apresentam em comum a presença de unidades estruturais ácidas, representadas pelo grupamento ácido carboxílico em (7), (8) e (38) e sulfonamida em (37), próximas a regiões conformacionalmente restritas. Outra característica comum nestes compostos inclui a presença de uma unidade hidrofóbica, rica em életrons, representada pelos anéis quinolínico e indólico presentes em suas estruturas (Figura 11)

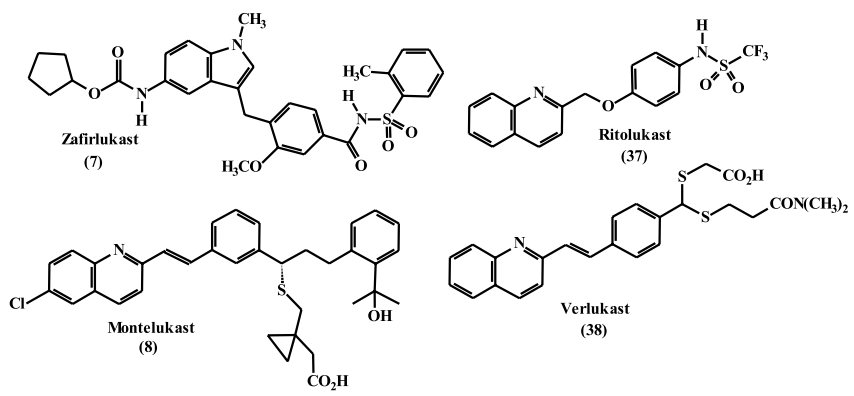

Figura 11. Exemplos de antagonistas de receptores $\mathrm{Cys} L T_{1}$ estruturalmente não relacionados ao $\mathrm{LTD}_{4}$ elou FPL 55712

O estudo da SAR em famílias congêneres de derivados quinolínicos com propriedades CysLTant, permitiu a identificação de contribuições farmacofóricas distintas, a saber: a) subunidade quinolínica, responsável por interações hidrofóbicas ou por ligação de hidrogênio com o receptor $C y s \mathrm{LT}_{1}$; b) subunidade estrutural ácida, representada por grupamentos do tipo ácido carboxílico ou isósteros, como tetrazola e sulfonilimida, que interagem com o biorreceptor envolvendo interações iônicas ou ainda por ligações de hidrogênio e, finalmente; c) subunidade hidrofóbica espaçadora, que separa as duas primeiras, ou seja, subunidades quinolínica e ácida, interagindo com o receptor $C y s \mathrm{LT}_{1}$ por meio de interações hidrofóbicas ${ }^{105-107}$. Adicionalmente, os dados de SAR desta classe sugeriram a importância do padrão de substituição do anel aromático central, visto que regioisômeros de posição são significativamente menos ativos ${ }^{105-108}$ (Figura 12). 


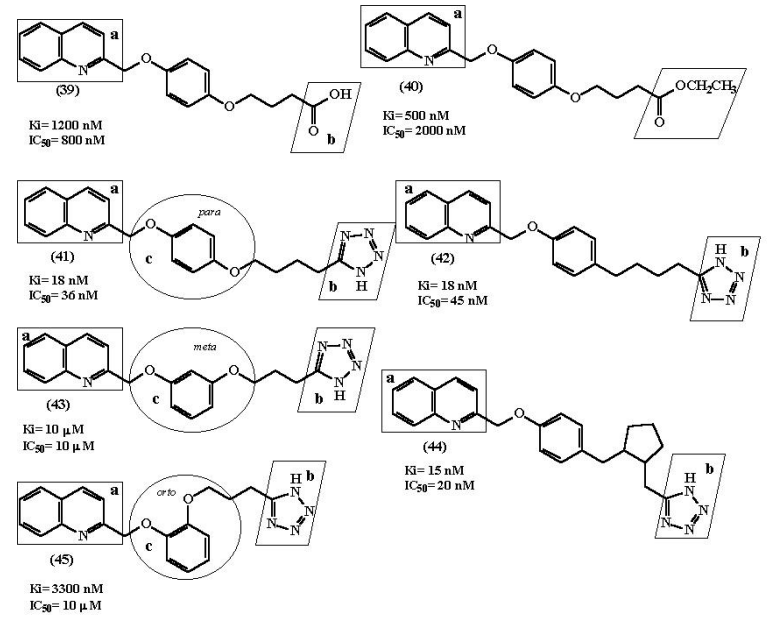

Figura 12. Exemplos de antagonistas de receptores $\mathrm{Cys}_{2} T_{1}$ estruturalmente não relacionado ao $\mathrm{LTD}_{4}$ elou FPL 55712, evidenciando as principais subunidades estruturais presentes nestes derivados tais como as unidades quinolínica (a), ácida (b), e aromática espaçadora (c)

Face à complexidade de fenômenos bioquímicos e celulares envolvidos na fisiopatologia da asma, associações terapêuticas tem sido empregadas na prática clínica, para seu tratamento. Desta forma, a administração concomitante de fármacos broncodilatadores (agonistas $\beta_{2}$ adrenérgicos) e antiinflamatórios (glicocorticóides), a exemplo do Beclotamol ${ }^{\circledast}$ e Seretide ${ }^{\circledR}$, comercializados pelos laboratórios Zambon e GlaxoSmithKline, respectivamente, exemplificam esta estratégia (Figura 13). O reconhecimento da eficácia terapêutica destas associações, provocaram o estudo de novas abordagens terapêuticas, desta feita voltadas para a identificação de novos candidatos a fármacos simbióticos, atuando, simultaneamente ao nível de mais de um biorreceptor, envolvido nesta fisiopatologia ${ }^{109}$.

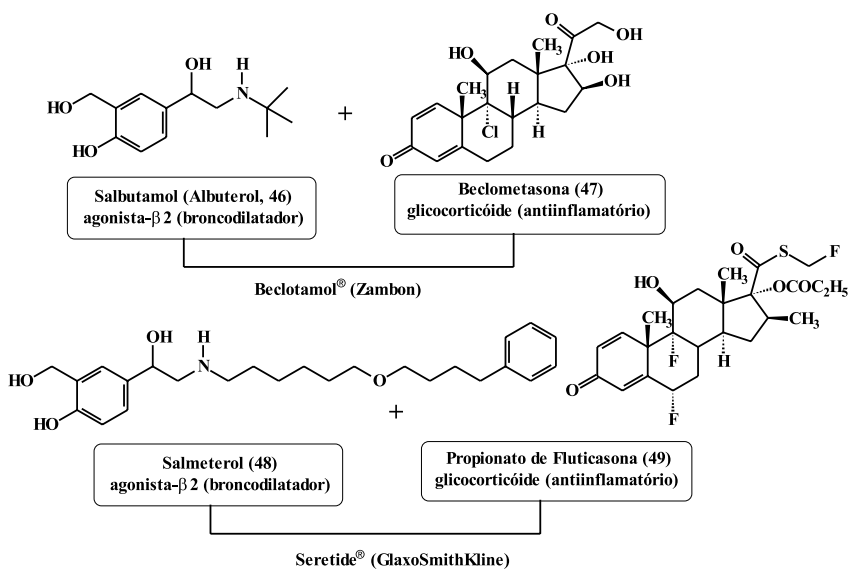

Figura 13. Associações terapêuticas de fármacos broncodilatadores e antiinflamatórios para o tratamento da asma brônquica

Neste contexto, vimos estudando em nosso laboratório ${ }^{111-113}$ a obtenção de um novo candidato a protótipo de fármaco antiasmático, planejado como agente simbiótico, explorando mecanismo de ação convergente por inibição da síntese de tromboxana $\mathrm{A}_{2}\left(\mathrm{TXA}_{2}\right)$ e do antagonismo de receptores Cys $\mathrm{LT}_{1}$. Estes esforços de pesquisa resultaram na identificação do composto LASSBio 341, derivado áci- do pirazolo[3,4-b]tieno[2,3-d]piridínico (51), estruturalmente planejado como híbrido do montelukast (8), fármaco antiasmático que atua como antagonista de receptores $C y s \mathrm{LT}_{1}$ e do ozagrel $(50)^{110}$, fármaco inibidor da tromboxana sintase (TXS), lançado no mercado com o nome comercial de Cataclot $^{\circledR}$ (Figura 14). Este novo derivado híbrido (51) possui como principais características estruturais para a atividade TXSi o grupamento ácido carboxílico terminal (b) (Figura 14), comum aos antagonistas $C y s \mathrm{LT}_{1}(c f .8)$ e o átomo de nitrogênio básico (a) distante adequadamente do termino ácido. Como requisitos estruturais mínimos à atividade $C y s \mathrm{LT}_{1}$, esta substância apresenta o núcleo pirazolo-piridínico, planar (c) (Figura 14) como isóstero à unidade quinolínica de (8) e contento o sítio básico (a). Ademais, apresenta uma subunidade hidrofóbica periférica (d), representada pelo anel para-clorofenila substituindo o sistema heterotricíclico pirazolo[3,4-b]tieno[2,3-d]piridínico. Este novo derivado LASSBio341 apresentou $\mathrm{IC}_{50}$ de $43,7 \mathrm{mM}$ nos bioensaios de inibição da contração induzida por $\mathrm{LTD}_{4}$ em traquéias de cobaias e $\mathrm{IC}_{50}$ de $0,14 \mu \mathrm{M}$ na inibição da agregação plaquetária induzida por ácido araquidônico em plasma rico em plaquetas de coelhos, respectivamente (Figura $14)^{111}$. Estes resultados ratificam a importância do planejamento racional na busca de novos candidatos a fármacos antiasmáticos e representam a descoberta de novo padrão molecular útil como protótipo de agentes duais para o tratamento da asma brônquica atuando ao nível de receptores Cys $\mathrm{LT}_{1}$ e inibidor da TXS.

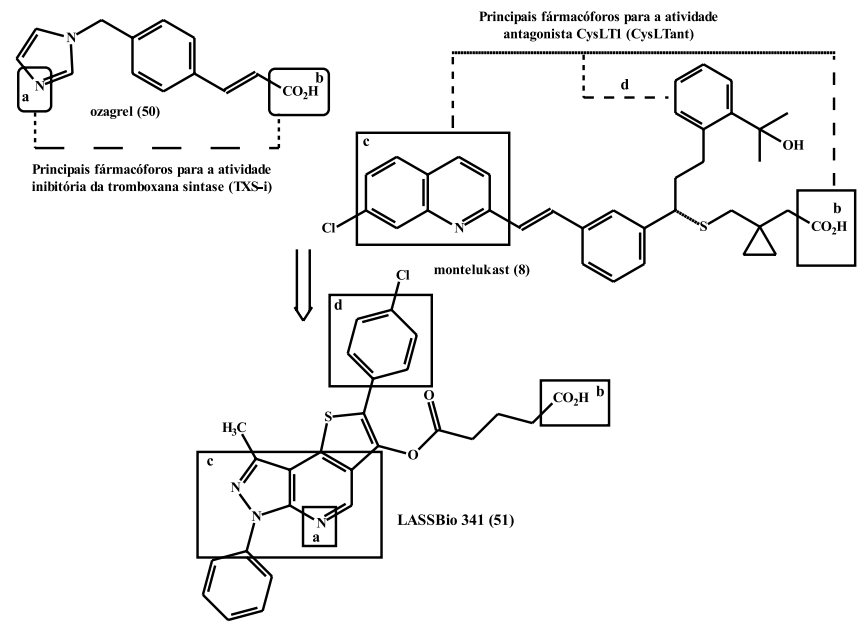

Figura 14. Gênese do composto LASSBio 341 (51), desenhado por hibridação molecular do montelukast (8) e do ozagrel (50)

\section{CONCLUSÕES}

O tratamento moderno da asma brônquica previne a participação dos leucotrienos cisteínicos nos eventos celulares e vasculares característicos do processo inflamatório, associados à sua potente atividade broncoconstritora, $c a$. 1000 vezes mais potente que a própria histamina, consolidando a abordagem antileucotriênica para o tratamento curativo e preventivo da asma brônquica.

Cumpre salientar ainda o surgimento de novas possíveis abordagens terapêuticas baseadas na terapia gênica, na utilização de moduladores de citocinas, e.g. anticorpos monoclonais antiinterleucinas (anti-IL-4, IL-5 e IL-13) e anti-TNF $\alpha$, que apresentam, entretanto, como limitação a ser superada, a indução de resposta antígeno-anticorpo, que resulta na perda de eficácia terapêutica com o decorrer do uso clínico, e no desenvolvimento de efeitos adversos deletérios devido à inibição das ações pleiotrópicas destas citocinas $^{26,61,65}$. 


\section{GLOSSÁRIO SELECIONADO*}

Antiasmáticos: Classe terapêutica responsável pelo tratamento e controle da sintomatologia associada à asma brônquica, classificados, genericamente, em fármacos broncodilatadores e antiinflamatórios.

Anticorpo monoclonal: Anticorpo específico para um determinado antígeno produzido por hibridoma de células $\mathrm{B}$.

Anticorpo: molécula de glicoproteína (Ig), produzida por linfócitos B, que se liga com alto grau de especificidade e afinidade a moléculas de antígenos.

Antígenos: móleculas de natureza química distinta que se ligam a anticorpos evocando resposta imunológica específica.

Antiinflamatórios: Classe terapêutica responsável pela prevenção e controle de fisiopatologias de origem inflamatória, sendo classicamente dividida em antiinflamatórios do tipo não esteróides (AINES), que tem como representante clássico o ácido acetilsalicílico, e os antiinflamatórios do tipo esteróide a exemplo dos corticosteróides, e.g., dexametasona.

Artrite reumatóide: Tipo de artrite caracterizada por sua natureza deformante e pela inflamação crônica do tecido conjuntivo.

Artrite: Inflamação das articulações.

Biodisponibilidade: Termo que expressa a taxa ou concentração de fármaco que atinge a circulação sistêmica a partir do seu sítio de administração.

Catabolismo: Biotransformação de compostos químicos complexos em compostos estruturalmente mais simplificados, freqüentemente acompanhada pela liberação de energia.

Citocinas: Proteínas ou glicoproteínas biossintetizadas por células do sistema imunológico, a partir de estímulos antigênicos ou microbiológicos, exercendo ações do tipo autócrina, parácrina e endócrina, responsáveis pelas respostas imunológicas e inflamatórias.

$\mathbf{E D}_{50}$ : Dose de fármaco necessária para atingir $50 \%$ do efeito farmacológico desejado.

Fármacos simbióticos: Substâncias que manifestam ação simultaneamente sobre dois grupos de biorreceptores ou enzimas, por possuírem características moleculares que permitem o reconhecimento pelos diferentes receptores.

Hibridoma: Linhagem de células derivadas de fusão celular ou hibridização celular entre linhagens de linfócitos normais e imortalizados.

$\mathbf{I C}_{\mathbf{5 0}}$ : Concentração requerida para atingir $50 \%$ do efeito inibitório máximo.

Índice terapêutico: Relação existente entre a dose efetiva e a dose letal, expressa pela razão dos valores de $\mathrm{LD}_{50}$ e $\mathrm{ED}_{50}$ de um determinado fármaco.

Mediadores químicos: Substâncias endógena ou exógenas que uma vez ativadas participam, desencadeando, mantendo e amplificando os diversos processos envolvidos na resposta inflamatória.

Meia-vida: Tempo necessário para eliminar metade da dose administrada de um determinado fármaco: $T_{1 / 2}$

Pleiotrópica: Refere-se à capacidade de uma citocina em agir sobre diferentes tipos celulares.

Psoríase: Condição patológica caracterizada pela erupção de maculopápulas avermelhadas, descamativas e limitadas, minúsculas e confluentes. As lesões ocorrem sobretudo nos cotovelos, joelhos, couro cabeludo e tronco.

\section{REFERÊNCIAS}

1. Hay, D. W. P.; Torphy, T. J.; Undem, B. J.; Trends Pharmacol. Sci. 1995, 16,304 ..

2. Melillo, G.; Melillo, E.; Clin. Appl. Immunol. Rev. 2001, 1, 235.

3. Hegele, R.G.; Immunopharmacology 2000, 48, 257.

4. Rabinovitch, N.; Gelfand, E. W.; Leung, D. Y. M.; Allergy 1999, 54, 662.

5. Holt, P. G.; Macaubas, C.; Stumbles, P. A.; Sly, P. D.; Nature 1999, 402, B12.

6. Corry, D. B.; Kheradmand, F.; Nature 1999, 402, B18.

7. Sandford, A. J.; Paré, P. D.; Am. J. Respir. Crit. Care 2000 161, S202.

8. Ritz, S. A.; Gajewska, B. U.; Stämpfli, M. R.; Jordana, M.; J. Allergy Clin. Immun. 2000, 106, S206.

9. Lemanske-Jr, R. F.; J. Allergy Clin. Immun. 2000, 105, S633.

10. Vignola, A. M.; Kips, J.; Bousquet, J.; J. Allergy Clin. Immun. 2000, 105, 1041.

11. O’Byrne, P. M.; Am. J. Respir. Crit. Care 2000, 161, S186.

12. Schmidt, D.; Rabe, K. F.; J. Allergy Clin. Immun. 2000, 105, 673.

13. Calhoun, W. J.; Sedgwick, J.; Busse, W. W.; Ann. N. Y. Acad. Sci. 1991 629,62 .

14. Holgate, S. T.; Sampson, A. P.; Am. J. Respir. Crit. Care 2000, 161, S147.

15. Gleich, G. J.; J. Allergy Clin. Immun. 2000, 105, 651.

16. Burney, P. G. J.; Chinn, S.; Rona, R. J.; Brit. Med. J. 1990, 300, 1306.

17. Cookson, W.; Nature 1999, 402, B5.

18. Busse, W. W.; J. Allergy Clin. Immun. 2000, 105, S583.

19. Arrighi, H. M.; Ann. Allergy Asthma Im. 1995, 74, 321.

20. Lotufo, P. A.; Benseñor, I. J. M.; de Lolio, C. A.; Rev. Saúde Pública 1995, 29,434

21. Lange, P.; Ulrik, C. S.; Vestbo, J.; Lancet 1996, 347, 1285.

22. Mormile, F.; Chiappini, F.; Feola, G.; Ciappi, G.; J. Clin. Epidemiol. 1996, 49, 1459

23. Holt, S.; Pearce, N.; New Zeal. Med. J. 2000, 113, 39.

24. Hurd, S.; Chest 2000, 117, 1S.

25. Barnes, P. J.; Jonsson, B.; Klim, J. B.; Eur. Respir. J. 1996, 9, 636

26. Barnes, P. J.; Eur. J. Int. Med. 2000, 11, 2.

27. Campos, H. S.; Pulmão RJ 2000, 9, 14

28. Barnes, P. J.; Chung, K. F.; Page, C. P.; Pharmacol. Rev. 1988, 40, 49

29. Williams, T. J.; Das, A.; Von Uexkull, C.; Nourshargh, S.; Ann. N. Y. Acad. Sci. 1991, 629, 73.

30. Page, C. P.; Ann. N. Y. Acad. Sci. 1991, 629, 38.

31. Holgate, S. T.; Lancet 1997, 350, 5.

32. Romagnani, S.; J. Allergy. Clin. Immun. 2000, 105, 399.

33. Capron, M.; Jouault, T.; Prin, L.; Joseph, M.; Ameisen, J. C.; Butterworth, A. E.; Papin, J. P.; Kusnierz, J. P.; Capron. A.; J. Exp. Med. 1986, 164, 72.

34. Sánchez-Mejorada, G.; Rosales, C.; J. Leukoc. Biol. 1998, 63, 521.

35. Campbell, I. D.; Immunol. Rev. 1998, 163, 11.

36. Turner, H.; Kinet, J. P. S.; Nature 1999, 402, B24 Suppl. S.

37. Williams, C. M. M.; Galli, S. J.; J. Allergy Clin. Immun. 2000, 105, 847.

38. Kobayashi, T.; Miura, T.; Haba, T.; Sato, M.; Serizawa, I.; Nagai, H.; Ishizaka, K. J.; Immunol. 2000, 164, 3855.

39. Oliver, J. M.; Kepley, C. L.; Ortega, E.; Wilson, B. S.; Immunopharmacology 2000, 48, 269.

40. Abbas, A. K.; Lichtman, A. H.; Pober, J. S.; Cellular and Molecular Immunology, 4ㄹ ed., W. B. Saunders Company, 2000, cap. 11, p. 235.

41. Prous, J. R.; Therapeutic Targets 1994, 19, 119.

42. Bell, R. L.; Summers, J. B.; Harris, R. R.; Ann. Rep. Med. Chem. 1997, 33,149 .

43. Lipworth, B. J.; Lancet 1997, 350, 18.

44. Katsunuma, T.; Fujita, K.; Mark, J. C. W.; Barner, P. J.; Ueno, K.; Irikura, Y.; J. Allergy Clin. Immun. 2000, 106, S104.

45. Gross, N. J.; New. Eng. J. Med. 1988, 319, 486.

46. Miyamoto, K.; Kurita, M.; Ohmae, S.; Sakai, R.; Sanae, F.; Takagi, K.; Eur. J. Pharm-Molec. PH 1994, 267, 317.

47. Braman, S. S.; Drugs 1996, 51, 415.

48. Jacobs, R. T.; Veale, C. A.; Wolanin, D. J.; Ann. Rep. Med. Chem. 1992, 127, 109.

49. Zhang, M-Q.; Sato, Y. F.; Timmerman, H.; J. Med. Chem. 1995, 38, 2472.

50. Glaser, K. B.; Mobilio, D.; Chang, J. Y.; Senko, N.; Trends Pharmacol. Sci. 1993, 14, 92.

51. Itoh, K.; Int. Arch. Allergy Imm. 1998, 115, 120.

*Este glossário foi baseado nos livros :

1- Barreiro, E. J.; Fraga, C. A. M.; Química Medicinal: As bases moleculares da ação dos fármacos, Art Med Editora Ltda.: Porto Alegre, 2001.

2- Abbas, A. K.; Lichtman, A. H.; Pober, J. S.; Cellular and molecular immunology, $4^{\text {th }}$ ed., Saunders Company: New York, 2000. 
52. Tamaoki, J.; Kondo, M.; Nakata, J.; Nagano, Y.; Isono, K.; Nagai, A.; Chest 2000, 118, 73 .

53. Chung, K. F.; Barnes, P. J.; Drugs 1988, 35, 93.

54. Djuric, S. W.; Huff, R. M.; Penning, T. D.; Clare, M.; Swenton, L.; Kachur, J. F.; Villani-Price, P.; Krivi, G. G.; Pyla, E. Y.; Warren, T. G.; Bioorg. Med. Chem. Lett. 1992, 2, 1371.

55. McMillan, R. M.; Walker, E. R. H.; Trends Pharmacol. Sci. 1992, 13, 323.

56. Costello, J. F.; Ann. N.Y. Acad. Sci. 1991, 629, 7.

57. Lemanske-Jr, R. F.; Drugs Today 1999, 35, 605.

58. Barnes, P. J.; Am. J. Resp. Crit. Care 1999, 160, S72; Vianna, E. O.; Martin, R. J.; Drugs Today 1998, 34, 341.

59. Hay, D. W. P.; Barnette, M. S.; Ann. Rep. Med. Chem. 1999, 34, 111

60. FredWong, W. S. F.; Koh, D. S. K.; Biochem. Pharmacol. 2000, 59, 1323.

61. Hedley, M. L.; Adv. Drug Deliver. Rev. 2000, 44, 195.

62. Naito, Y.; Fukaya, C.; Imagawa, T.; Nakamura, N.; Drugs Future 1998, 23, 1083.

63. Chung, K. F.; Barnes, P. J.; Thorax 1999, 54, 825.

64. Tavakkoli, A.; Rees, P. J.; Drugs 1999, 57, 1

65. Riffo-Vasquez, Y.; Pitchford, S.; Spina, D.; Int. J. Biochem. Cell Biol. 2000, 32,833 .

66. Teixeira, M. M.; Gristwood, R. W.; Cooper, N.; Hellewell, P. G.; Trends Pharmacol. Sci. 1997, 18, 164.

67. Barnette, M. S.; Prog. Drug Res. 1999, 53, 195.

68. Barnes, N. C.; Am. J. Respir. Crit. Care 2000, 161, S73; Barnes, P. J.; Trends Pharmacol. Sci. 2000, 21, 194

69. Calhoun, W. J.; Curr. Opin. Pharmacol. 2001, 1, 230.

70. Spector, S. L.; Ann. Allerg. Asthma Im. 1995, 75, 463.

71. Chung, K. F.; Barnes, P. J.; Drugs Today 1998, 34, 375

72. Piper, P. J.; Conroy, D. M.; Costello, J. F.; Evans, J. M.; Green, C. P.; Price, J. F.; Spencer, D. A.; Ann. N. Y. Acad. Sci. 1991, 629, 112.

73. Samuelsson, B.; Angew. Chem., Int. Ed. 1982, 21, 902.

74. Samuelsson, B.; Haeggstrom, J. Z.; Wetterholm, A.; Ann. N. Y. Acad. Sci. 1991, 629, 89

75. Parker, C. W.; Ann. Rev. Immunol. 1987, 5, 65.

76. Kumlin, M.; Dahlén, S. E.; Biochem. Biophys. Acta 1990, 1044, 201.

77. Ueda, N.; Kaneko, S.; Yoshimoto, T.; Yamamoto, S.; J. Biol. Chem. 1986, 261,7982 .

78. Yamamoto, S.; Prostag. Leukotr. Ess. 1989, 35, 219

79. Peters-Golden, M.; Brock, T. G.; Am. J. Respir. Crit. Care 2000, 161, S36.

80. Lam, B. K.; Austen, K. F.; Am. J. Respir. Crit. Care 2000, 161, S16.

81. Rådmark, O. P.; Am. J. Respir. Crit. Care 2000, 161, S11.

82. Thunnissen, M. M. G. M.; Nordlund, P.; Haeggström, J. Z.; Nat. Struc. Biol. 2001, $8,131$.

83. Hammarström, S.; Örning, L.; Bernström, K.; Mol. Cell. Biochem. 1985, $69,7$.

84. Denzlenger, G.; Guhlmann, A.; Scheuber, P. H.; Wilker, D.; Hammer, D. K.; Keppler, D.; J. Biol. Chem. 1986, $261,15601$.

85. Gorenne, I.; Norel, X.; Brink, C.; Trends Pharmacol. Sci. 1996, 17, 342.

86. Rovati, G. E.; Capra, V.; Nicosia, C.; Trends Pharmacol. Sci. 1997, 18, 148

87. Dahlén, S-E.; Am. J. Respir. Crit. Care 2000, 161, S41.

88. Nicosia, S.; Capra, V.; Ravasi, S.; Rovati, E.; Am. J. Respir. Crit. Care 2000, $161, \mathrm{~S} 46$.

89. Lynch, K. R.; O’Neil, G. P.; Liu, Q.; Im, D-S.; Sawyer, N.; Metters, K. M.; Coulombe, N.; Abramovitz, M.; Figueroa, D. J.; Zeng, Z.; Connolly, B. M.; Bai, C.; Austin, C. P.; Chateauneu, A.; Stocco, R.; Greig, G. M.; Kargman, S.; Hooks, S. B.; Hosfield, E.; Williams-Jr, D. L.; FordHutchinson, A.; Caskey, C. T.; Evans, J. F.; Nature 1999, 399, 789.
90. Heise, C. E.; O’Dowd, B. F.; Figueroa, D. J.; Sawyer, N.; Nguyen, T.; Im, D-S.; Stocco, R.; Bellefeuille, J.L.; Abramovitz, M.; Cheng, R.; WilliamsJr, D. L.; Zeng, Z.; Liu, Q.; Ma, L.; Clements, M. K.; Coulombe, N.; Liu, Y.; Austin, C. P.; George, S. R.; O’Neil, G. P.; Metters, K. M.; Lynch, K. R.; Evans, J. L.; J. Biol. Chem. 2000, 275, 30531.

91. Harper, R. W.; Herron, D. K.; Bollinger, N. G.; Sawyer, J. S.; Baldwin, R. F.; Roman, C. R.; Rinkema, L. E.; Fleisch, J. H.; J. Med. Chem. 1992, 35, 1191 .

92. Salmon, J. A.; Garland, G. L.; Prog. Drug Res. 1995, 45, 9.

93. Zhang, M-Q.; Zwaagstra, M. E.; Nederkoorn, P. H. J.; Timmerman, H.; Bioorg. Med. Chem. Lett. 1997, 7, 1331.

94. Zwaagstra, M. E.; Schoenmakers, S. H. H. F.; Nederkoom, P. H. J.; Gelens, E.; Timmerman, H.; Zhang, M-Q.; J. Med. Chem. 1998, 41, 1439.

95. Palomer, A.; Pascual, J.; Cabré, F.; García, L.; Mauleón, D.; J. Med. Chem. 2000, 43, 392.

96. Snyder, D. W.; Fleish, J. H.; Ann. Rev. Pharmacol. Toxicol. 1989, 29, 123.

97. Rodger, I. W.; Am. J. Respir. Crit. Care 2000, 161, S7.

98. Cohen, N.; Weber, G.; Banner, B. L.; Lopresti, R. J.; Schaer, B.; Fucella, A.; Zenchoff, G. B.; Chin, A. M.; Todaro, L.; O’Donnell, M.; Welton, A. F.; Brown, D.; Garippa, R.; Crowley, H.; Morgan, D. W.; J Med. Chem. 1989, 32, 1842

99. Mead, B.; Patterson, L. H.; Smith, D. A.; J. Pharm. Pharmacol. 1981, 33, 682

100. Fleisch, J. R.; Rinkema, L. E.; Haisch, K. D.; Swanson-Bean, D.; Goodson, T.; Ho, P. P.; Marshall, W. S.; J. Pharmacol. Exp. Ther. 1985, 223, 148.

101. Bendele, A. M.; Hoover, D. M.; Van Lier, R. B.; Foxworthy, P. S.; Eacho, P. I.; Fund. Appl. Toxicol. 1990, 15, 676.

102. Perchonock, C. D.; Uzinskas, I.; Ku, T. W.; McCarthy, M. E.; Erhard, K. F.; Gleason, J. G.; Weichman, B. M.; Mucatelli, R. M.; Devan, J. F.; Tucker, S. S.; Vickery, L. M.; Wasserman, M. A.; Mong, S.; Scote, M. O.; Chi-Rosso, G.; Wu, H-L.; Crooke, S. T.; Newton, J. F.; J. Med. Chem. 1986, 29, 1142.

103. Aharony, D.; Krell, R. P.; Ann. N. Y. Acad. Sci. 1991, 629, 125

104. Brooks, C. D. W.; Summers, J. B.; J. Med. Chem. 1996, 39, 2629

105. Musser, J. H.; Kubrak, D. M.; Chang, J.; DiZio, S. M.; Hite, M.; Hand, J. M.; Lewis, A. J.; J. Med. Chem. 1987, 30, 400

106. Galemmo-Jr, R. A.; Johnson-Jr, W. H.; Learn, K. S.; Lee, T. D. Y.; Huang, F-C.; Campbell, H. F.; Youssefyeh, R.; O'Rourke, S. V.; Schuessler, G.; Sweeney, D. M.; Travis, J. J.; Sutherland, C. A.; Nuss, G. W.; Carnathan, G. W.; Van Inwegen, R. G.; J. Med. Chem. 1990, 33, 2828.

107. Youssefyeh, R.D.; Magnien, E.; Lee, T. D. Y.; Chan, W-K.; Lin, C. J.; Galemmo, R. A.; Johnson, W. H.; Tan, J.; Campbell, H. F.; Huang, F-C.; Noss, G. W.; Carnathan, G. W.; Sutherland, C. A.; Van Inwegen, R. G.; J. Med. Chem. 1990, 33, 1186.

108. Sprecher, A. V.; Gerspacher, M.; Beck, A.; Kimmel, S.; Wiestner, H.; Anderson, G. P.; Niederhauser, U.; Subramanian, N.; Bray, M. A.; Bioorg. Med. Chem. Lett. 1998, 8, 965.

109. Baldwin, J. J.; Lumma, W. C.; Lundell, G. F.; Ponticello, G. S.; Raab, A. W.; Engelhardt, E. L.; Hirschmann, R.; Sweet, C. S.; Scriabine, A.; J. Med. Chem. 1979, 22, 1284

110. Korosawa, M.; Clin. Ther. 1995, 17, 2

111. Cardoso, C. R.; de Brito, F. C. F.; da Silva, K. C. M.; Miranda, A. L. P.; Fraga, C. A. M.; Barreiro, E. J.; Bioorg. Med. Chem. Lett. 2002, 12, 9.

112. Lima, L. M.; de Brito. F. C. F.; de Souza, S. D.; Miranda, A. L. P.; Rodrigues, C. R.; Fraga, C. A. M.; Barreiro, E. J.; Bioorg. Med. Chem. Lett. 2002, 12, 1533.

113. Lima, L. M.; Castro, P.; Machado, A. L.; Fraga, C. A. M.; Lugnier, C.; Gonçalves de Moraes, V. L.; Barreiro, E. J.; Bioorg. Med. Chem. 2002, 10, 3067 . 